\title{
Labour Taxation, Job Creation and Job Destruction - Focusing on the Role of Wage Setting
}

\author{
Pekka Sinko \\ Government Institute for Economic Research , \\ Secretariat of the Economic Council, \\ University of Helsinki and HECER
}

Discussion Paper No. 68

June 2005

ISSN 1795-0562

HECER - Helsinki Center of Economic Research, P.O. Box 17 (Arkadiankatu 7), FI-00014 University of Helsinki, FINLAND, Tel +358-9-191-28780, Fax +358-9-191-28781, E-mail info-hecer@helsinki.fi, Internet www.hecer.fi 


\title{
Labour Taxation, Job Creation and Job Destruction - Focusing on the Role of Wage Setting*
}

\begin{abstract}
We study the effects of labour taxation on wages, unemployment and efficiency in a search equilibrium model with endogenous job destruction. Three alternative models of wage setting are considered: Nash bargain, monopoly union and efficiency wages. The adverse employment effect of labour taxes is mainly due to prolonged unemployment spells and less due to increased job destruction. Magnitude of the effect varies considerably depending on the wage setting model. If wage setting is based on bargaining, a pure increase in the tax progression reduces unemployment, improves the relative position of low-income workers and facilitates the emergence of low-productivity jobs.
\end{abstract}

JEL Classification: J41, J51, J64, H2.

Keywords: labour taxation, wage setting, employment, search and matching models.

\section{Pekka Sinko}

Secretariat of the Economic Council

Prime Minister's Office

P.O. Box 23

FI-00023 Government

FINLAND

e-mail: pekka.sinko@vnk.fi

* This paper is based on an essay of my doctoral thesis presented at the University of Helsinki, September 2004. An earlier version was presented at the EALE 2002 Conference in Paris and FDPE Labour economics seminar in Helsinki, November 2002. I wish to thank Erkki Koskela, Jukka Pirttilä, Matti Tuomala and the participants of the two sessions for their helpful comments. 


\section{Introduction}

High and persistent European unemployment has given rise to a number of economic policy advice programmes directed to reduce the structural causes of joblessness. Most of these programmes include suggestions to mitigate the tax burden on labour, in particular on low-income wage earners (see for example EU, 2000 and EEAG, 2002). Similar targets have been adopted by national governments as, for example, a recent evaluation study shows for the case of Finland (Ministry of Labour, 2002). A typical policy package along these lines would increase the tax allowances on earned income and thereby mitigate the taxation of low-wage workers. The idea that cutting labour taxes might help to bring down unemployment also finds support in some recent economic studies. A frequently cited example is Prescott (2004), who argues that higher labour taxation is capable of explaining the poor employment performance of the major European countries when compared to the United States.

As we read it, neither of these approaches puts much emphasis on the wage setting and the country differences in the related institutions. In the advice programmes, the recommendation for cutting taxes especially among low-paid workers, is traditionally justified by their presumably higher labour supply and demand elasticities (see e.g. CEPR, 1995). In Prescott's analysis, the wages are assumed to be determined in a competitive manner and no institutional differences between countries are allowed for. The conclusion is that marginal tax rates should be cut in Europe.

The negligence of wage setting is somewhat unsatisfactory given the relatively large literature on the importance of the wage formation in transmitting the effects of the tax policy on the employment outcomes. This literature, focusing on the imperfectly competitive labour markets, has shown that the effects of taxation greatly depend on the prevailing wage setting mechanism. The two most widely used wage setting frameworks utilized in these studies are union models (e.g. Hersoug, 1984, Koskela and Vilmunen, 1996 and Hansen et al., 2000) and efficiency wage models (e.g. Hoel, 1990, Pisauro,1991 and Sörensen, 1999). One of the key findings is that - different from the competitive set-up - a pure increase in the tax progression may lead to wage moderation and thereby improve employment. This result, which has found support in a number of empirical studies such as Lockwood and Manning, (1993), Holmlund and Kolm (1995), Aronsson et al., (1997) and more recently - Schneider (2005), has been more rigorously developed in the 
union models. In the efficiency wage models, the results concerning the desireability of tax progression are somewhat more mixed (see e.g. Rasmussen, 1998). Recently labor taxation has been analyzed also in the search theoretic framework by e.g. Pissarides (1998) and Mortensen and Pissarides (2002).

The purpose of the present paper is to contribute to this discussion by considering the effects of labor taxation and tax progression in a search equilibrium model with endogenous job creation and job destruction. In particular, we want to find out how alternative assumptions of wage setting affect the employment outcomes. For that purpose, we consider three alternative hypotheses of wage determination: the Nash bargain, "monopoly union" and efficiency wages ${ }^{1}$. Our analysis identifies two potentially important reasons for a more careful modelling of wage setting in the tax policy analysis: First, differences in the wage setting mechanisms can explain why European countries may be able bear a higher tax burden on labor and why tax cuts alone would not necessarily bring European unemployment down to the U.S. level. This is particularly so, if the European labor market can be characterized by wage bargaining and the U.S. by efficiency-wage-type of pay setting. Second, the positive employment effects of tax progression in the case of noncompetitive wage setting may provide another justification for the tax allowances of the low-income workers even if labor demand elasticities would not differ systematically between income groups. This view is highlighted by the fact that tax allowances already constitute a remarkable source of progressivity in personal income taxation in the OECD-countries (Wagstaff and van Doorslaer, 2001).

In our model, originating from Mortensen and Pissarides (1994), the job destruction decision is made endogenous by assuming that the filled vacancies are subject to a stochastic and idiosyncratic productivity shock with a given probability distribution. This allows us to consider the effects of taxation at two separate margins: the job creation and the job destruction. As for the tax instruments, our analysis covers proportional and progressive tax on labor income as well as a proportional payroll tax. The inclusion of alternative widely used models of non-competitive wage setting enables an interesting comparison between them and allows us to consider to what extent the results derived in the static models carry over to the search equilibrium framework.

\footnotetext{
${ }^{1}$ We write "monopoly union" in quotation marks because - as discussed in more detail below - our specification due to Mortensen and Pissarides (1999) differs somewhat from the standard meaning of the term. The exact assumptions of the alternative wage setting models is discussed in more detail below.
} 
Furthermore, as noted by Pissarides (1998), the inclusion of alternative wage setting mechanisms in the tax policy analysis can be justified by the lack of a definitive model for the European labor market.

We find, not surprisingly, that labor taxes have a harmful effect on the steady state employment, irrespective of the wage formation mechanism ${ }^{2}$. The adverse effect is mainly due to reduced labor market tightness and the consequent increase in the unemployment duration. However, the magnitude of the effect varies, depending on the wage setting specification. In particular, employment turns out to be much less sensitive to taxation in the models involving wage bargaining. Our results also suggest that increased tax progression may improve employment with low or even non-existent efficiency cost if wages are set in a bargaining framework. Moreover, we argue that in these models tax progression increases the take-home pay of low-productivity workers and promotes the emergence of less productive jobs.

The present paper extends the existing literature by considering the effects of tax progression in a model with endogenous job destruction and by analyzing the robustness of this relationship to alternative assumptions concerning the wage setting mechanism. Our approach is closely related to Pissarides (1998), who compares the effects of labor taxes and tax progression within alternative models of the labor market including a stylized search model. However, our analysis is cast in a search equilibrium with endogenous job destruction and is thereby more general ${ }^{3}$. Mortensen and Pissarides (1999) and (2002) provide an analysis of labor taxation in a model with endogenous job destruction and standard Nash bargain over wages, but do not consider the effects of tax progression. Mortensen and Pissarides (1999) introduce alternative models of wage formation, but do not analyze their implications for the effects of tax policies.

The structure of the paper is as follows. Section 2 introduces the basic model and the alternative models of wage determination. Section 3 presents

\footnotetext{
${ }^{2}$ There are some recent studies with opposite results: Altenburg and Straub (2002) show that proportional labour taxes can actually improve employment in a combined efficiency wage and union bargaining framework. Their result stems from decomposing the effective labour input into (endogenous) effort and employment. Kilponen and Sinko (2005) find a positive employment effect of proportinal labour income tax in a monopoly union model with an individual supply of working hours. Their finding is conditional on centralised wage setting and high enough marginal utility of publicly provided goods.

${ }^{3}$ On the other hand, we do not explicitly consider the role of unemployment benefits and their indexation as Pissarides does, but implicitly confine ourselves to the case where unemployment benefits are fixed in real terms.
} 
simulations of tax policy effects in alternative model specifications. A summary of the results and some concluding remarks are presented in section 4 . Some of the technical details are presented in the appendices A-D.

\section{The Model}

The framework of our analysis is a model of equilibrium unemployment with endogenous job creation and job destruction originally presented in Mortensen and Pissarides (1994) ${ }^{4}$. In the model, the job destruction decision is made endogenous by assuming that the filled vacancies are subject to a stochastic and idiosyncratic productivity shock with a given probability distribution. The shock arrives at a fixed Poisson rate. The firm then chooses an endogenous reservation productivity $R$ and destroys the jobs whose productivity falls below that threshold.

A remarkable difference to the standard model with exogenous job destruction (see e.g. Pissarides, 2000, Chapter 1) is that now jobs are heterogeneous with respect to productivity. At any point of time there is a continuum of filled vacancies whose productivity lies in the range between the reservation productivity and the highest attainable productivity. It is assumed - consistently with free entry and profit maximizing behavior - that a new match always has the highest productivity. For simplicity, the highest productivity is normalized to unity.

In our basic model, the wage rate of a job is determined in a decentralized Nash bargain once the match is formed, and subsequently renegotiated after each productivity shock. In what follows, we introduce labor income taxation to this basic model and derive the equilibrium with taxes. We then proceed to consider the effects of taxation under two alternative hypotheses of wage determination: the monopoly union (section 2.5) and the efficiency wage (section 2.6) settings.

\footnotetext{
${ }^{4}$ Our basic model deviates to some extent from Mortensen and Pissarides (1994). For example, we do not allow for a general productivity shock, bacause it is less interesting for the issue at hand. Our notation follows closely that of Pissarides (2000), Chapter 2.
} 


\subsection{Individuals}

Since jobs are only created at the highest productivity level $(x=1)$ the expected present value of unemployment search $U$ is defined by

$$
r U=b-a+m(\theta)(W(1)-U)
$$

where $b$ is the value of leisure or "home production", $a$ is the net cost of search per period, $r$ is the discount rate of interest and $W(1)$ is the expected present value of a work offer. Furthermore, the endogenous probability of encountering a vacancy $m(\theta)$, is a function of the labor market tightness defined as the ratio of vacancies to the number of the unemployed $\theta \equiv v / u$. As usual, we assume a constant returns to scale matching technology implying $m^{\prime}(\theta)>0, m^{\prime \prime}(\theta)<0^{5}$. For a worker employed in a job with productivity $x$ we have

$$
r W(x)=(1-t) w(x)-g+\delta\left[\int_{0}^{1} \max (W(z), U) d F(z)-W(x)\right]
$$

where $w$ is the wage rate and $\delta$ is the exogenous probability of an idiosyncratic productivity shock. The distribution of the shock is captured by a cumulative density function $F(x), F^{\prime}(x)>0$, defined over the interval $[0,1]$. After a shock, the worker either continues working in a job with a new productivity level or becomes unemployed if the value of the job falls below that of unemployment search i.e. $W(x)<U$. Furthermore, $g$ and $t$ are income tax parameters such that the income tax paid by an employed worker per period is

$$
T=g+t w(x)
$$

For $t>0, g=0$ implies a tax schedule that is proportional to income. With $g<0(g>0)$ taxation is progressive (regressive) in the sense that average tax rate increases (decreases) with income ${ }^{6}$. Parameter $g$ can be interpreted as a tax credit or a lump tax, respectively. The after tax wage or take-home pay of a job with productivity $x$ is then given by $(1-t) w(x)-g^{7}$.

\footnotetext{
${ }^{5}$ To be exact, $m$ is the matching function divided by the number of unemployed. Petrongolo and Pissarides (2001) provide more discussion on the theoretical underpinnings of matching functions and a survey on the empirical evidence.

${ }^{6}$ See e.g. Lambert (2001). For the alternative definions of tax progression see Musgrave and Thin (1948).

${ }^{7}$ An alternative and essentially identical specification to capture a potentially progressive taxation would be $T=t(w(x)-c)$, where $c$ is a lump-sum allowance rather than a
} 


\section{$2.2 \quad$ Firms}

Since jobs are created at the highest productivity level, the value of a vacancy $V$ is given by

$$
r V=-c+q(\theta)(J(1)-V)
$$

where $c$ is the cost of a vacancy per period, $q(\theta)=\theta^{-1} m(\theta)$ is the probability of encountering an unemployed worker and $J(1)$ is the value of a filled vacancy. The value of a filled vacancy with productivity $x$ is given by

$$
r J(x)=x-(1+s) w(x)+\delta\left[\int_{0}^{1} \max (J(z), V) d F(z)-J(x)\right]
$$

where $s$ is the proportional payroll tax levied on the employer. Notice that the expected duration of a vacancy is determined simply by $1 / q(\theta)$. Differentiating then allows us to define the elasticity of the expected duration of a vacancy with respect to the number of vacancies $\varepsilon \equiv \partial \log (1 / q(\theta)) / \partial \log v$, that turns out to be important determinant of the efficiency of the model equilibrium $^{8}$.

\subsection{Nash Bargain on Wages}

The standard assumption in this class of models is that the surplus associated with a job match is shared between the workers and the firms in a decentralized Nash bargain over wages. Workers and firms are assumed to be "small" in the sense that they do not consider the effects of their action on aggregate variables, in particular on the value of unemployment search and the value of vacancies. Given the transferable utility between the two parties, a Nash bargain guarantees the individual rationality of job destruction decisions (Mortensen and Pissarides, 1999). In our notation, the match specific Nash wage is determined by

$$
w(x)=\arg \max (W(x)-U)^{\beta}(J(x)-V)^{1-\beta}
$$

where $0<\beta<1$ is an exogenous parameter reflecting the relative "bargaining power" of the worker. In the absence of further information it is natural (and

tax credit. With $c>0(c<0)$ taxation would be progressive (regressive) with respect to before-tax income.

${ }^{8}$ It is straightforward to show that in the special case of a Cobb-Douglas matching technology, $\varepsilon>0$ will be constant. 
standard) to assume the symmetric case where $\beta$ equals one half. It can be shown (see e.g. Pissarides, 2000) that if $\beta$ happens to coincide with the elasticity of the expected duration of a vacancy with respect to the number of vacancies $(\beta=\varepsilon)$, the equilibrium produced by the model with no taxes is socially efficient. This result holds for homogenous of degree one matching functions and is referred to as the Hosios condition (Hosios, 1990) ${ }^{9}$.

The first order condition related to (6) can be written in the form (see Appendix A for details)

$$
\frac{W(x)-U}{J(x)-V+W(x)-U}=\frac{\beta(1-t)}{(1+s)-\beta(s+t)}
$$

where the numerator of the left hand side, $W(x)-U$ is the surplus of a worker and the denominator $J(x)-V+W(x)-U$ is the total surplus of a match. Expression (7) thus conveniently shows the effect of taxes on the worker's relative share of the surplus from a match. Differentiating the right hand side shows that an increase in either of the proportional tax rates, $s$ or $t$, reduces the worker's relative share. Intuitively, this is because taxes that are proportional to wages induce a common incentive to wage moderation for the worker and the firm, as noticed by Pissarides (2000). The per head tax $g$ does not have this property and only affects the total surplus thus leaving the relative shares unaffected. Therefore, $g$ is absent from the right hand side of (7). Also notice that in the absence of taxes the worker's share is simply determined by $\beta$.

\subsection{Equilibrium with Taxes}

In the model with endogenous job destruction, the flow of workers into unemployment is dictated by $\delta F(R)(1-u)$. The flow of workers out of unemployment through the matching process is determined by $m(\theta) u$. Equating the two flows allows us to solve for the steady state rate of unemployment as follows

$$
u=\left(1+\frac{m(\theta)}{\delta F(R)}\right)^{-1}
$$

\footnotetext{
${ }^{9}$ Satisfaction of the Hosios condition implies that the externalities related to the search are internalised in the wage setting. This is not generally the case under the Nash bargain (Pissarides, 2000).
} 
With $m^{\prime}(\theta), F^{\prime}(R)>0$, equation (8) shows that the equilibrium rate of unemployment decreases in the labor market tightness and increases in the reservation productivity ${ }^{10}$.

The labor market equilibrium can be defined by imposing the conditions for free entry and mutual acceptance of job destruction. Free entry for firms is assumed to bring the value of a vacancy to zero

$$
V=0
$$

With (9) holding, the mutual acceptance of job destruction implies ${ }^{11}$

$$
W(R)-U=J(R)=0
$$

It takes some algebra (see Appendix B) to show that after introduction of the two conditions (9) and (10) we can express the equilibrium as a solution to a set of two independent equations in the labor market tightness and the reservation productivity. The first one,

$$
\frac{(1+s)}{(1-t)}(b-a+g)+\frac{\beta c \theta}{(1-\beta)}=R+\frac{\delta}{(r+\delta)} \int_{R}^{1}(z-R) d F(z)
$$

is the job destruction condition in the presence of taxation and constitutes an upward sloping curve in $(\theta, R)$ space. For given labor market tightness, (11) implies a positive relationship between the tax parameters and the reservation productivity. Thus, an increase in any of the tax parameters implies an upward shift of the curve. The second equation,

$$
c=\frac{1-\beta}{r+\delta} q(\theta)(1-R)
$$

is the job creation condition and constitutes a downward sloping curve in $(\theta, R)$ space. The labor market equilibrium in the presence of taxation is characterized by the labor market tightness and reservation productivity determined by the two equations (11) and (12). It is worth noting that the tax instruments do not enter the job creation condition (12). In other words,

\footnotetext{
${ }^{10}$ Equation (8) can also be interpreted as the equation of the Beveridge curve, as shown in Pissarides (2000).

${ }^{11}$ Alternatively, (10) follows from (7) and (9) and the condition that total surplus from a match is zero at the reservation productivity i.e. $J(R)-V+W(R)-U=0$.
} 
with a given labor market tightness, the reservation productivity is sufficient to transmit the effects of the tax changes to a job creation decision based on the free entry condition (9).

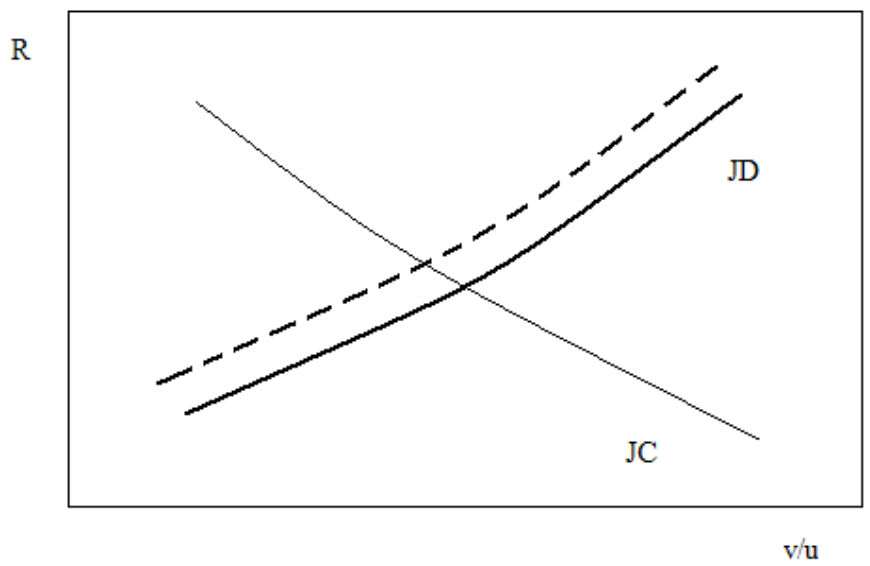

Figure 1 Effect of higher labour taxes in the model with the Nash bargain on wages: the upward sloping job destruction schedule shifts up and to the left with a consequent drop in the labour market tightness $(\mathrm{v} / \mathrm{u})$ and an increase in the reservation productivity $R$.

The effects of exogenous changes in the tax rates can be presented diagrammatically in the $(\theta, R)$ space: An increase in either of the tax parameters shifts the job destruction schedule to the left, whereas the job creation schedule remains stable ${ }^{12}$. Consequently, labor market tightness drops and reservation productivity increases in response to higher taxation (Figure 1). With the help of equations (7) and (B.3) it is then straightforward to show that the value of a filled vacancy $J(x)$ as well as the worker's surplus $(W(x)-U)$ decline owing to higher taxes. Consequently, the total surplus of a match with productivity $x$ is reduced. As for the wage rate, rearranging equation

\footnotetext{
${ }^{12}$ Using the job destruction condition (11) it is straightforward to show that the introduction of either a proportional tax on income or a proportional payroll tax has identical effects on the equilibrium if the rates are chosen such that $(1+s)=(1-t)^{-1}$. Thus, the so-called wedge argument (see Layard et al.,1991) applies and the real effects of the two taxes are independent of the nominal incidence.
} 
(B.8) reveals that an increase in any of the three tax parameters unambiguously reduces the after tax wage $(1-t) w(x)-g$. With reference to (8), it is equally clear that an increase in any of the tax parameters leads to an increased flow into unemployment and a reduced flow out of unemployment at the initial level of employment and consequently, into a higher rate of unemployment in the steady state. These findings can be summarized by the following proposition:

Proposition 1 In the model where wages are determined in a standard decentralized Nash bargain between firms and workers, an increase in proportional or per head labor tax causes an increase in the reservation productivity $R$ and a decline in the labor market tightness $\theta$. Consequently, worker's share of the match surplus and the after tax wage decline and equilibrium unemployment increases.

The results stated in Proposition 1 are in line with the findings of Mortensen and Pissarides (1999), who show that an increase in the proportional payroll tax increases reservation productivity and reduces labor market tightness and Mortensen and Pissarides (2002), who show that the per head labor income tax has similar effects.

Following Pissarides (2000), it is straightforward to show that the equilibrium with taxes is socially efficient if the matching technology satisfies the Hosios condition $\beta=\varepsilon$ already discussed above, and the tax parameters are chosen to satisfy the following condition

$$
g=\frac{-(b-a)(s+t)}{1+s}
$$

which in effect makes (11) equal to the case with no taxes. For an interpretation of (13), it is helpful to notice that the per head tax $g$ essentially corresponds to a subsidy to leisure or home production. What (13) then states is that if the value of home production net of search cost $(b-a)$ is subsidized at a rate equal to the effective tax rate on wages, the overall tax system is neutral with respect to job creation and destruction. However, if $\beta \neq \varepsilon$ the no tax equilibrium is inefficient and "full efficiency" cannot be restored with the available tax instruments ${ }^{13}$.

\footnotetext{
${ }^{13}$ If $\beta \neq \varepsilon$, an approriate combination of the tax instruments can, however, improve efficiency over the no tax equilibrium, as we will show below in one of the numerical simulations.
} 


\subsection{Monopoly Union Wage Setting}

In the basic model above, we employed the standard assumption of search models that wages are an outcome of a Nash bargain between firms and workers. When setting the wage, firms and workers took the action of other agents, and therefore the aggregate variables, as given. Also, the parameter $\beta$ reflecting worker's bargaining power and relative share of the surplus was exogenously fixed.

In this section, we consider an alternative model of wage setting that involves an endogenous determination of $\beta$. In particular, we employ the "monopoly union" formulation suggested by Mortensen and Pissarides (1999) where - in order to preserve the individual rationality of job destruction - the monopolistic bargaining position of a trade union is captured by allowing the union to decide upon the value of $\beta$ rather than directly dictate the wage rate. When setting $\beta$, the union takes full account of the implications of its act for the decisions made by the individual agents, that is the workers and firms engaged in the job matching. After $\beta$ has been set, the Nash wage rule (6) applies to the individual matches and firms and workers respond by making the appropriate job creation and destruction decisions.

Having stated the basic structure of the problem, we are left with the determination of the union's objective. Importantly, Pissarides (2000) shows that if the worker's share parameter was set to maximize the expected utility

of an unemployed worker, it would be chosen to be equal to the elasticity of the expected duration of a vacancy with respect to the number of vacancies. Thus, the Hosios condition would be satisfied and the equilibrium would be efficient. Though theoretically important, this is hardly a realistic objective for a workers' union.

We employ, perhaps more realistically, the approach suggested by Mortensen and Pissarides (1999), where the objective of the union is to maximize the expected utility of a median member (see also Booth, 1995). With more than half of the members working, the median member will be an employed worker. Utilizing the notation introduced in the previous section, we can apply equations (7), (9) and (B.3) to write down the value function of the median worker

$$
W\left(x_{m}\right)=U+\frac{(1-t) \beta\left(x_{m}-R\right)}{(r+\delta)(1+s)}
$$

where $x_{m}>R$ is the productivity of the job held by the median member. According to (14), the value of a job held by the median member is a mark-up 
over the value of unemployment search $U$. The size of the mark-up increases in the job productivity $x_{m}$ as well as in the worker's share parameter $\beta$, and decreases in the reservation productivity $R$. Intuitively, high reservation productivity renders jobs less secure and thereby reduces the premium over unemployment experienced by those holding a job.

The problem of the union is then to maximize the right hand side of (14) with respect to $\beta$, taking account of the indirect effect through $U$ and $R$ as implied by the underlying model of matching behavior by workers and firms. Differentiating (14) with respect to $\beta$ and setting equal to zero yields the first order condition for the union optimum

$$
\frac{\partial W\left(x_{m}\right)}{\partial \beta}=\frac{\partial U}{\partial \beta}+\frac{(1-t)}{(r+\delta)(1+s)}\left(\left(x_{m}-R\right)-\beta \frac{\partial R}{\partial \beta}\right)=0
$$

To develop (15) further, we need to derive suitable expressions for $U$ and $R$, respectively. To facilitate this, we assume that matching technology is of Cobb-Douglas type i.e. $m(\theta) \equiv \theta^{\rho}$ and the productivity shock is evenly distributed in the interval ]0,1[ (see Appendix C). Starting with $U$, we apply equation (B.4) to derive

$$
r U+g=\frac{(1-t)}{(1+s)} \frac{2 R r+\delta R^{2}+\delta}{2(r+\delta)}
$$

which reflects the positive relationship between the value of unemployment search $U$ and the reservation productivity $R$ : The unemployed are, ceteris paribus, better off when the reservation productivity is high, jobs are volatile and the difference between unemployment and employment is relatively small. Solving (16) explicitly for $U$, differentiating with respect to $\beta$ and substituting for $\partial U / \partial \beta$ into (15) allows us to rewrite the first order condition as follows

$$
\frac{(1-t)\left(x_{m}-R\right)}{(r+\delta)(1+s)}+\frac{(1-t)(R \delta+(1-\beta) r)}{r(r+\delta)(1+s)} \frac{\partial R}{\partial \beta}=0
$$

Equation (17) conveniently decomposes the effect of $\beta$ on the median worker's utility into a direct effect and an indirect effect through $R$ : The first positive term on the left hand side accounts for the direct effect of a higher worker's share that increases with productivity of the median worker $x_{m}$. The second term reflects the induced change in reservation productivity and thus in the "job security" experienced by the median worker. Since the 
other two terms in the left hand side of (17) are strictly positive, we can conclude that $\frac{\partial R}{\partial \beta}<0$, at the union's optimum.

To derive an expression for $\frac{\partial R}{\partial \beta}$, we first utilize (11) and (12) to derive

$$
\frac{(1-\beta)^{\rho}(1-R)}{r+\delta}\left(\frac{R(2 r+R \delta)+\Theta(s, t, g)}{2 \beta(r+\delta) c}\right)^{-(1-\rho)}=c
$$

where $\Theta(s, t, g) \equiv \delta-2(1+s)(1-t)^{-1}(r+\delta)(b-a+g)$ is a constant incorporating the tax parameters. Equation (18) thus implicitly defines $R$ as a function of $\beta$. For a plausible choice or parameters it traces a concave curve in the $\beta, R$-space. Applying the implicit function rule to (18) we then find

$$
\frac{\partial R}{\partial \beta}=\frac{(1-\rho-\beta)(1-R)}{\beta(1-\beta)\left(1+2\left(2 R r+R^{2} \delta+\Theta(s, t, g)\right)^{-1}(1-\rho)(1-R)(R \delta+r)\right)}
$$

where the denominator is positive for a reasonable range of values of the reservation productivity. Equation (19) defines the response of the firms' reservation productivity to a marginal increase in the workers' share. Notice that setting the right hand side of (19) equal to zero implies $\beta=1-\rho$, which constitutes the Hosios condition in the present set-up with Cobb-Douglas matching technology and (13) holding. This notion reflects the property of the underlying model that the reservation productivity achieves its maximum at the social optimum (Mortensen and Pissarides, 1999) ${ }^{14}$. For the present set-up, $\frac{\partial R}{\partial \beta}<0$ implies that $\beta>1-\rho$. In other words, $\beta$ is higher, and consequently, the reservation productivity $R$ is lower, than would be socially optimal.

\footnotetext{
${ }^{14}$ Also notice that letting $x_{m} \rightarrow R$ in (17) produces the case of the unemployed median member as a limiting outcome and implies $\frac{\partial R}{\partial \beta}=0$ at the optimum. This reproduces the result of Pissarides (2000) that the unemployed worker's optimum coincides with the efficient outcome.
} 


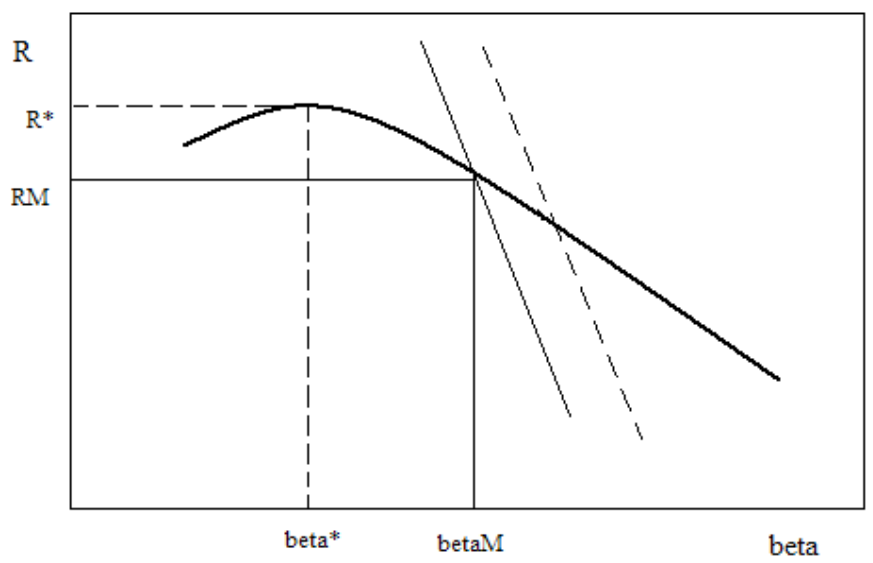

Figure 2 The equilibrium of the monopoly union case depicted in the $(\beta, R)$ space. The reservation productivity $R_{M}$ is lower and the workers share $\beta_{M}$ is higher than in the efficient outcome $\left(\beta^{*}, R^{*}\right)$. An increase in the median voter's productivity induces a rightward shift in the downward sloping locus defined by (20) and increases the deviation from efficiency.

Finally, substituting (19) for $\frac{\partial R}{\partial \beta}$ in (17) and some manipulation yields

$$
\frac{2(1-\rho)(1-R)(R \delta+r)}{2 R r+\delta R^{2}+\Theta(s, t, g)}=\frac{R(1-\rho)-\beta x_{m}+(1-\beta-\rho)\left(\frac{\delta R(R-1)}{r(1-\beta)}-1\right)}{\beta\left(x_{m}-R\right)}
$$

where $\Theta(s, t, g)$ is as defined above in connection to (18). Equation (20) defines a locus in $(\beta, R)$ - space that satisfies the "monopoly union condition". Assuming that the second order condition is satisfied, the locus is downward sloping. Intuitively, high reservation productivity implies less secure jobs and induces the median worker to put more weight on the value of unemployment search and less to the premium while working. Therefore she/he prefers lower worker's share $\beta$.

The labor market equilibrium $(\beta, R, \theta)$ under the monopoly union regime is defined by the equations (11), (12), (20). The wage rate is then determined by (B.8). Figure 2 depicts the equilibrium in the $\beta, R$-space as an intersection of the of the two curves defined by equations (18) and (20). By differentiating 
(20) with respect to $x_{m}$ and $\beta$ it is possible to show that an increase in the median voter's productivity induces a rightward shift of the locus, causing an increase in $\beta$ and a further reduction in $R$ (see Figure 2). We summarize these findings by the following lemma:

Lemma 1 In the model where a monopoly union maximizes the utility of a median member, the parameter $\beta$ reflecting the worker's share in the Nash bargain is set above the socially efficient level. This implies lower reservation productivity and insufficient job destruction in the equilibrium. The deviation from efficiency increases with the productivity of the median member.

Lemma 1 adds to the findings of Mortensen and Pissarides (1999), who argue that, in general, the monopoly union formulation leads to a higher worker's share and a lower reservation productivity than would be socially optimal. Intuitively, employed median worker does not fully accommodate the implications of a low reservation productivity on the unemployed and therefore chooses a worker's share higher than would be socially optimal. When setting $\beta$, the union aims at equating the immediate gain from a higher worker's share to the indirect loss due to a lower reservation productivity. Since, as reflected in (17), the immediate gain from higher $\beta$ for the median worker is proportional to the difference between his/her productivity and the reservation productivity, the deviation from efficiency is the larger, the larger is $x_{m}$.

As for the effects of taxation, differentiating (18) with respect to the tax parameters for a given $\beta$ shows that higher taxes cause an upward shift in the curve. Similarly, differentiation of (20) shows that an increase in one of the tax parameters causes a shift to the right of this locus. Thus, we cannot infer the effect of higher taxation on reservation productivity and on the worker's share parameter. Consequently, and different from the standard model, the effect of taxes on the labor market tightness $\theta$ as well as on wages and employment remain a priori ambiguous under the monopoly union specification.

The sharing rule (7), which defines the worker's share of the surplus still holds with the exception that $\beta$ is no longer constant at the equilibrium. In addition to the negative direct effect, the proportional tax rates $s$ and $t$ now have an indirect effect through $\beta$, which may either mitigate or reinforce the direct effect. As for the per head tax $g$, there is still no direct effect on the worker's share. However, a change in $g$ does affect the worker's share 
indirectly through $\beta$. Thus, the "neutrality" result of the per head tax of the previous section does not hold in the monopoly union set-up. We summarize these findings in the form of a proposition:

Proposition 2 In the model where a monopoly union maximizes the utility of a median member, the effects of either a proportional or per head labor tax on reservation productivity $R$, labor market tightness $\theta$ and the worker's share parameter $\beta$ are a priori ambiguous. Different from the standard Nash bargain model, the division of the match surplus between workers and firms is not neutral with respect to a per head tax.

Proposition 2 spells out the fact that assuming a slightly different wage setting mechanism has a considerable effect on the implications of labor taxes in the model. In the standard, decentralized Nash bargain model the behavioral response to taxation is based on the workers and firms mutual interest to avoid excess tax payments. In the present set-up, this consideration is accompanied by an upper level response by the union that perceives the effects of taxation on job creation and destruction. In the numerical simulations we show that the latter response leads to a decline in $\beta$ after a tax hike and consequently, more moderate increase in the unemployment when compared to the standard model.

\subsection{Efficiency Wages}

As another alternative mechanism of wage determination in the present framework, we consider an efficiency wage specification based on the well known model of Shapiro and Stiglitz (1984). In this set-up, wage setting is decentralized similar to the standard model of section 2.4 above. However, different from the standard model, wage determination is based solely on the consideration of the firm. To develop this idea further, we start with the model by Mortensen and Pissarides (1999) and extend it by the introduction of labor taxation. As an essential feature of the model, employed workers can either exert effort or "shirk". Exerting effort is costly in terms of lost leisure and the workers need some incentive to do so. Because the productivity of those supplying effort is higher, it is in the interest of the firms that their employees exert effort. If a firm finds someone shirking, he or she will be dismissed and will end up searching for a new job. However, monitoring is costly and the firms must content with spot checks that only provide a positive probability of detecting a shirker. The solution to the problem is that 
firms end up paying a wage rate that makes the workers indifferent between exerting effort and shirking.

In this set-up, utilizing the notation introduced above and allowing for the tax instruments as defined in (3), the valuation of a job by an employed worker exerting effort can be written as

$$
r W_{e}(x)=(1-t) w-g+\delta\left[U F(R)+S_{e}(x)-W_{e}(x)\right]
$$

where $S_{i}=\int_{R}^{1} W_{i}(x) d F(x), i=e, s$ is the average value of a filled job for a worker exerting effort $e$ and for a shirker $s$, respectively. Similarly, for an employed worker not exerting effort (shirker) we have

$$
\begin{aligned}
r W_{s}(x)= & (1-t) w-g+e+\delta\left[U F(R)+S_{s}(x)-W_{s}(x)\right] \\
& +\mu\left(U-W_{s}(x)\right)
\end{aligned}
$$

where $e$ is the value of the extra leisure from not exerting effort and $\mu$ is the monitoring frequency. According to (22), monitoring implies an increased risk of becoming unemployed for a shirker as reflected by the last term on the right hand side.

Since all workers are identical, the value of unemployment search and thus, the threat point, is equal to all employed workers. Therefore, there is no need for the firm to differentiate wages according to job productivity and the wage rate will be uniform across jobs, as we already anticipated in the notation in equations (21) and (22). Consequently, the valuation of a job for a worker only depends on whether he or she exerts effort i.e. $W_{i}(x)=W_{i}, \forall x, i=e, s$. Imposing indifference between exerting effort and "shirking" $W_{e}=W_{s}=W$ into (21) and (22) then yields the no-shirking condition

$$
e=\mu(W-U)
$$

According to (23), the worker is indifferent between working and shirking if the disutility of effort is just equal to the expected loss from shirking. Notice that (21) can now be rewritten as

$$
r W=(1-t) w-g+\delta F(R)(U-W)
$$

For the value of unemployment search, recall (1) to derive

$$
r U=b+m(\theta)(W-U)
$$


where, for simplicity, we have set $a=0$ i.e. abstracted from the separate search $\operatorname{cost}^{15}$. The efficiency wage can then be solved from (23), (24) and (25) to get

$$
w=\frac{b+g}{1-t}+\frac{e(r+\lambda(\theta)+\delta F(R))}{\mu(1-t)}
$$

According to (26), wages depend positively on both labor market tightness $\theta$ and reservation productivity $R$. Intuitively, labor market tightness puts an upward pressure on wages because finding another job becomes easier for a potential shirker. Wages increase in reservation productivity because jobs became more insecure with higher $R$. Furthermore, for given labor market tightness and reservation productivity, wages decrease in the monitoring frequency $\mu$ and increase in the value of extra leisure to a shirker $e$ as well as in the proportional and per head income taxes, $t$ and $g$. Slightly rearranging (26) shows that for given labor market tightness and reservation productivity, the after tax wage $(1-t) w-g$ is independent of the taxes. Intuitively, as long as the threat point of a potential shirker has not changed, the after tax remuneration needed to attract effort is invariable. Whether after tax wages increase or decrease after a tax hike thus depends on the indirect effects through $\theta$ and $R$.

In the efficiency wage set up, there is no mutual acceptance of job destruction, but the decision is based on the consideration of the firm. With the zero profit condition (9) binding, the reservation productivity is thus determined by the condition $J(R)=0$. Substituting wage equation (26) in (A.2) under (9) and rearranging gives

$$
(r+\delta) J(x)=x-(1+s)\left(\frac{b+g}{1-t}+\frac{e(r+\lambda(\theta)+\delta F(R))}{q(1-t)}\right)+\delta S_{J}
$$

which corresponds to (B.2) in the basic model. Developing a Taylor series around $J(R)=0$ yields

$$
J(x)=\frac{1}{r+\delta}(x-R)
$$

Applying (27) to $x=R$ and further substituting (28) for $J(z)$ gives

$$
\frac{(1+s)}{1-t}\left(b+g+\frac{e}{q}(r+\lambda(\theta)+\delta F(R))\right)=\frac{\delta}{r+\delta} \int_{R}^{1}(z-R) d F(z)+R
$$

\footnotetext{
${ }^{15}$ This assumption is made to simplify the notation and does not affect the key results.
} 
which is the job destruction condition in the efficiency wage model and constitutes an upward sloping schedule in the $(\theta, R)$-space by an appropriate choice of the exogenous parameters ${ }^{16}$. To derive another independent equation in the two unknowns, first notice that with (9) binding, (4) still implies (B.6). Then, apply (28) to $x=1$ and substitute (B.6) for the value of a job to get

$$
c=\frac{(1-R)}{r+\delta} q(\theta)
$$

which is the job creation condition in the efficiency wage model and constitutes a downward sloping curve in $(\theta, R)$-space.

By inspecting the equilibrium conditions, it is easy to see that the equivalence of the proportional income tax and the payroll tax still holds as long as the rates are chosen such that $(1+s)=(1-t)^{-1}$. Furthermore, in the efficiency wage set-up, the proportional income tax is equivalent to the per head tax as long as rates are chosen such that $g=t w^{17}$.

The efficiency wage equilibrium with taxes is the tuple $(R, \theta)$ defined by the intersection of curves (29) and (30). Similar to the basic model with the Nash bargain over wages, tax parameters only enter the job destruction condition (29). Differentiating (29) shows that an increase in any of the tax parameters causes a shift up and to the left for the job destruction curve. Since the job creation schedule remains stable, higher taxes unambiguously cause an increase in the reservation productivity and a decline in the labor market tightness. By (8), this implies a higher steady state rate of unemployment.

It is worth noting that combining (23), (9) and (B.3) we can derive the following expression for the worker's share of the surplus in the efficiency wage equilibrium

$$
\frac{W-U}{J(x)-V+W-U}=\left(1+\frac{q(x-R)}{e(r+\delta)}\right)^{-1}
$$

\footnotetext{
${ }^{16}$ Mortensen and Pissarides (1999) have shown that generally the job destruction schedule may be non-monotonic in the case of efficency wages and therefore multiple equilibria may arise.

${ }^{17}$ This can be verified by imposing $t=0$ and $g=t_{0} w$ into (26) and (29); the resulting equilibrium will be identical to the case where $t=t_{0}$ and $g=0$. It has been shown in models not allowing for search behaviour that the equivalence of proportional and per head taxes is a special feature of the Shapiro-Stiglitz model, which does not necessarily hold in more versatile extensions of the efficiency wage models (e.g. Pisauro, 1991 and Rasmussen, 1998).
} 
According to (31), the worker's share increases in $R$. For a given worker's share, a higher reservation productivity makes jobs more risky thereby reducing the utility difference between employment and unemployment workers and the expected loss from shirking. The satisfaction of no shirking condition then requires that the workers share increases with the reservation productivity.

Expression (31) reveals that the tax rates affect the worker's relative share only indirectly through the reservation productivity $R$, which - as argued above - increases with any one of the three tax parameters. Since the worker's share increases in $R$, as shown by (31), we can conclude that higher taxes increase the worker's relative share of the surplus in the efficiency wage specification. As for the wages, equation (26) reveals that the induced changes in the endogenous variables by a tax hike (higher $R$ and lower $\theta$ ) cause two opposite effects on the after tax wage. Consequently, the overall effect of taxation on take-home pay is ambiguous ${ }^{18}$. These findings can be summarized as follows:

Proposition 3 In the model where wages are determined according to a standard efficiency wage rule, an increase in proportional or per head labor tax causes an increase in the reservation productivity $R$ and a decline in the labor market tightness $\theta$. Consequently, worker's share of the match surplus and equilibrium unemployment increase, but the effect on the after tax wage is a priori ambiguous.

The finding that higher labor taxes increase the worker's share of the match surplus in the efficiency wage specification is in clear contrast to the two models involving wage bargaining analyzed in the previous sections. The wage moderation effect of proportional tax inherent to the bargaining models does not arise in the efficiency wage set-up where wage setting is driven by the no-shirking condition and taxes are borne by the firms.

\section{Numerical Simulations}

In the previous section we noticed that the effects of taxation differ considerably depending on the prevailing wage setting mechanism. However, the

\footnotetext{
${ }^{18}$ It turns out in the numerical simulations that the effect through lower labour market tightness dominates and the after tax wage drops if taxes are increased in the efficiency wage set-up.
} 
direction of the deviation of the wage and employment response was in most cases ambiguous. In this section we use numerical simulations to derive more specific employment responses to changes in the tax policy under the three alternative models of wage setting. The method also allows us to compare the magnitude of the tax effects in the different models.

To enable simulations, we specify the functional form of the matching function and the distribution of the productivity shock. In particular, we assume Cobb-Douglas matching technology $m(\theta) \equiv \theta^{\rho}$ and an evenly distributed productivity shock in the interval ]0,1[ (see Appendix C). We then choose some plausible numerical values for the exogenous parameters of the model.

Before turning to the simulations, we derive formulas for a few aggregate variables that will be useful in reporting the simulation results. Let us first define the unemployment incidence as $I \equiv \delta F(R)$ and the expected duration of an unemployment spell as $D \equiv \theta^{-\rho}$. According to (8) the steady state unemployment depends positively on the unemployment incidence and on the expected duration of an unemployment spell. To develop a measure for the overall efficiency, we notice that the steady state aggregate income net of search and recruiting costs $y$ can be defined as

$$
y=\left(F(R)+\int_{R}^{1} x d F(x)\right)(1-u)+(b-a-c \theta) u
$$

where the first term on the right hand side defines the total product in steady state with $F(R)$ representing the fraction of matches of type $x=1$. Finally, the total tax revenue (see Appendix D for the details) collected by the three taxes is given by:

$$
\begin{aligned}
& T= {\left[\left(\frac{(1-\beta)}{1-t}(b-a+g)+\frac{\beta}{1+s}\left(c \theta+1-\frac{1}{2}(1-R)^{2}\right)\right)(t+s)+g\right] } \\
& \times(1-u)
\end{aligned}
$$

In choosing the values for the exogenous parameters there are potentially two alternative paths to follow. One could choose the exogenous parameters of the model to reflect the stylized facts of some particular economy as for instance in Millard and Mortensen (1997) and Holm et al. (1999). Instead, we prefer using values that roughly correspond to the ones used in the earlier studies of policy impact by Pissarides (1998) and Mortensen and Pissarides (1999) and referring to a "stylized economy". Following the common practice, 
we set the matching function elasticity parameter $\rho$ so as to satisfy the Hosios condition in the case of a symmetric Nash bargain $(\beta=0.5)$. The quarterly discount rate $r$ is taken to be 1 per cent. The value of leisure $b$ is set at 0.6 to reflect the average replacement ratio provided by the unemployment insurance. The remaining parameter values are adjusted so as to produce a reasonably low unemployment rate ( 1.5 per cent) at the no-tax benchmark of the Nash bargain model. The extra parameters of the monopoly union model (median worker productivity $x_{m}$ ) and efficiency wage model (value of extra leisure $e$ and monitoring frequency $\mu$ ) are then chosen so that the unemployment rate with no taxes in these models is close to that in the Nash bargain model. The exact parameter values used in the simulations are presented in Table 1.

Table 1: The parameter values used in the model simulations. $a$ is the search cost per period, $b$ is the value of leisure gross of search cost, $c$ is the per period cost of holding a vacancy, $r$ is the (quarterly) rate of discount, $s$ is the payroll tax, $\rho$ is the matching elasticity parameter, $\delta$ is frequency of a productivity shock, $x_{m}$ is the productivity of the median worker, $e$ is the value of extra leisure for a shirker and $\mu$ is the monitoring frequency of the firm.

$\begin{array}{llllllllll}a & b & c & r & s & \rho & \delta & x_{m} & e & \mu \\ 0.2 & 0.6 & 0.2 & 0.01 & 0.0 & 0.5 & 0.03 & 0.98 & 0.1 & 0.5\end{array}$

\subsection{Proportional and per Head Taxation}

Let us first consider the effect of an exogenous increase in the proportional tax rate on labor income ${ }^{19}$. The results of a simulation where a 10 per cent tax on labor income was introduced are presented in Table 2, along the rows with $t=0.1, g=0$. The job creation rate is reduced and the introduction taxation leads to longer unemployment spells $(\Delta D>0)$. At the same time, the reservation productivity increases, causing more job destruction at a given level of employment. This quantitatively weaker effect, is reflected in the higher unemployment incidence $(\Delta I>0)$.

The two effects are qualitatively similar irrespective of the model specification. However, the magnitude of the employment effects differ depending

\footnotetext{
${ }^{19}$ Since - as predicted by the analytical results - the effects of a proportional payroll tax $s$ are identical to the effects of $t$,we focus only to the latter in the simulations.
} 
on the wage setting mechanism. In the efficiency wage model the effects are much larger than in the models with wage bargaining. This reflects the fact derived above in Section 2.6 that labor taxes increase the worker's share of the surplus in the efficiency wage model, thus promoting a stronger response of wages to a tax hike.

Table 2: Results from the simulations where either proportional or per head income taxation was introduced at rate $t=0.1$ or $g=0.1$, respectively. $D$ is the average duration of unemployment spells, $I$ is unemployment incidence and $u$ is unemployment rate. The symbol $\Delta$ refers to a percentage change.

$\begin{array}{llllll} & t & g & \Delta D & \Delta I & \Delta u \\ \text { Efficiency wage } & 0.1 & 0.0 & 33.2 & 0.4 & 33.5 \\ \text { Monopoly union } & 0.0 & 0.1 & 34.1 & 0.3 & 34.3 \\ & 0.1 & 0.0 & 3.6 & 0.1 & 3.5 \\ \text { Nash bargain }(\beta=0.5) & 0.0 & 0.1 & 8.5 & 0.25 & 8.6 \\ & 0.1 & 0.0 & 4.0 & 0.1 & 4.1 \\ & 0.0 & 0.1 & 9.8 & 0.25 & 9.9\end{array}$

In the monopoly union and Nash bargaining models, the wage and employment responses are much more modest, owing to the wage moderation effect inherent in wage bargaining discussed above in Section 2.3. A higher proportional tax rate reduces the worker's share of the surplus which facilitates a moderate wage response. In the monopoly union set-up this effect is by a downward adjustment of $\beta$. Accordingly, the negative employment effect is smallest in the monopoly union model.

The effects of an increase in the per head tax $g$, presented in Table 2 along the rows with $t=0.1, g=0$, are qualitatively similar to those of the proportional tax. The difference to the proportional tax is that the wage and employment response in the models with wage bargaining is now clearly stronger and quantitatively closer to the efficiency wage model. As noticed above in sections 2.3 and 2.4, a per head income tax does not directly reduce the worker's share of the match surplus in the models involving wage bargaining. It does so, however, indirectly through the lowered $\beta$ in the monopoly union specification. This is why the per head tax has a relatively strong effect on unemployment in the Nash bargaining model and a little weaker effect in the monopoly union specification. 


\subsection{Progressive Taxation}

To compare the response of the alternative wage determination models to tax progression, we simulated a simultaneous introduction of proportional wage $\operatorname{tax}(t=0.1)$ and a per head tax credit or subsidy, $g<0$. The size of the subsidy was adjusted to just exhaust the revenue raised by the proportional tax. Thus, the net revenue raised by the tax system is zero, implying $d T=0$. This set-up enables us to focus on the effects of pure progression of the tax system $^{20}$.

The results from the balanced budget simulations are presented in Table 3. As discussed above in section 2.6 the two taxes are essentially identical in the efficiency wage set-up. Since the balanced budget constraint implies $g=-t w$, a pure increase in progression has no effect on the labor market equilibrium in this case.

Table 3: Results from the simulations where progressive income taxation was introduced in a revenue neutral manner. $D$ is the average duration of unemployment spells, $I$ is unemployment incidence, $u$ is unemployment rate and $y$ aggregate income, reflecting overall efficiency. The symbol $\Delta$ refers to a percentage change.

$\begin{array}{lllllll} & t & g & \Delta D & \Delta I & \Delta u & \Delta y \\ \text { Efficiency wage } & 0.1 & -0.0985 & 0.0 & 0.0 & 0.0 & 0.0 \\ \text { Monopoly union } & 0.1 & -0.0986 & -4.5 & -0.15 & -4.59 & 0.0 \\ \text { Nash bargain } \beta=0.5 & 0.1 & -0.0986 & -5.13 & -0.15 & -5.18 & -0.004 \\ \text { Nash bargain } \beta=0.55 & 0.1 & -0.0987 & -5.14 & -0.15 & -5.19 & 0.008\end{array}$

In the Nash bargain and monopoly union models, a revenue neutral introduction of progressive taxation evokes wage moderation and reduces unemployment. The mechanisms behind the result are essentially those discussed above, in section 3.1 with the exception that $g$ is now a per head employment subsidy rather than a tax. The upward adjustment of $\beta$ mitigates the negative wage response in the monopoly union case and leaves the positive employment effect somewhat smaller than in the standard Nash bargain case.

As for the effect on aggregate output, it is worth noticing that despite the improved employment, efficiency drops in the Nash bargain model (third row of Table 3). This is a reflection of the fact discussed above in Section 2.4 that

\footnotetext{
${ }^{20}$ For simplicity, our starting point is the no tax equilibrium of each model, but the results should be applicable to cases with pre-existing (proportional) taxes as well.
} 
if "no tax equilibrium" satisfies the Hosios condition, the efficiency cannot be improved. This is exactly the case in our model if $\beta=0.5$ and $\rho=0.5$. However, this does not hold in a "second best" situation, where $\beta \neq 1-\rho$, as demonstrated in the final row of Table 3 showing the simulation results from the Nash bargain model with $\beta=0.55$. In this case, unemployment is too high in the initial equilibrium and efficiency improves after the introduction of taxation.

Finally, we notice that the policy package involving an increase in both the proportional tax and in the per head transfer affects workers differently depending on the productivity of their current job. As for the take-home pay of the workers, $(1-t) w(x)-g$, the wage related part declines and the per head part increases for any level of productivity. Because of the revenue neutrality, the two effects break even on average. Consequently, a threshold level of productivity exists at which the take-home pay remains unchanged after the introduction of the policy. For workers in jobs with productivity lower than the threshold, after tax wages will increase. Similarly, for workers with productivity higher than the threshold, after tax incomes will decline. Thus, the revenue neutral introduction of progressive taxation serves to improve the relative position of workers in the low productivity jobs. Moreover, the induced reduction in the reservation productivity $R$ implies that jobs with lower than before productive will become profitable. Thus, the tax policy serves to widen the range of profitable jobs towards the less productive occupations.

\section{Concluding Remarks}

We have considered the effects of labor taxation and tax progression in an equilibrium model of the labor market with endogenous job creation and job destruction. To focus especially on the role of wage setting, we embedded three alternative models of wage determination: in addition to the standard decentralized Nash bargain we considered the monopoly union and efficiency wage specifications originating from Mortensen and Pissarides (1999). The analytical results were complemented by numerical simulations of the resulting three distinctive models.

In all model specifications, the effects of a proportional income tax turned out to be equivalent to a proportional payroll tax and independent of the nominal incidence. Increases in either proportional or per head taxation have 
an adverse effect on employment at two separate margins: less vacancies are posted and more jobs are terminated. Our numerical simulations suggest that the former effect tends to be stronger and labor taxation is reflected mainly in the prolonged spells of unemployment. At the same time, the magnitude of the negative employment effects are smaller in the models with wage bargaining in comparison to the efficiency wage specification. This finding reflects the fact that higher taxes lead to a reduction of the worker's share of the match surplus in the bargaining models, but to an increase in that share in the efficiency wage specification.

Finally, we combine the two tax instruments in a revenue neutral manner to enable a pure increase in the tax progression. We find that the increased progression of labor taxes may improve employment with low or even nonexistent efficiency cost if wages are set in a bargaining framework. Moreover, we argue that in these models, increased progression increases the take-home pay of low-productivity workers and promotes the emergence of less productive jobs. In the efficiency wage set-up a pure increase in tax progression is neutral in terms of employment.

Despite the somewhat different framework, our results are broadly in line with those of Pissarides (1998), who suggests that a revenue- neutral increase in the tax progression comes close to a "free lunch". From the policy point of view, our findings might provide another justification for the tax reforms that aim to mitigate the tax burden of the low-income workers in Europe by introducing tax exemptions and increasing the lower limit for taxable income. Furthermore, to the extent that the European labor market can be characterized by wage bargaining and the U.S. by efficiency wage pay setting, our results shed some light to the relationship between taxation and employment in international comparisons such as Prescott (2004). According to our results, labor taxation and tax progression are less harmful to employment in the set-up where wages are bargained over. This is especially so, if some collective, economy wide institutions like trade unions are involved in the wage setting $^{21}$. Therefore, European economies may be capable of dealing with a higher tax burden with less damage to employment compared to the countries with a more competitive wage setting. A corollary to this idea is that tax cuts would not boost employment that strongly in Europe and the

\footnotetext{
${ }^{21}$ This conjecture finds some support in the recent empirical findings suggesting that the employment effects of labour taxes tend to be smaller in the corporatist economies (Daveri and Tabellini, 2000, Kiander et al, 2004).
} 
policies directed to bring employment to the U.S. level should therefore not put too much hope on lower taxation.

\section{A Derivation of the Nash Wage Rule}

First notice that (2) can be written as

$$
W(x)=\frac{(1-t) w(x)-g+\delta\left(U F(R)+S_{W}\right)}{r+\delta}
$$

where $R$ is the endogenous reservation productivity to be determined below and $S_{W}=\int_{R}^{1} W(z) F(z)$ is the average value for a worker of a filled job. Similarly, we can rewrite (5) as

$$
J(x)=\frac{x-(1+s) w(x)+\delta\left(V F(R)+S_{J}\right)}{r+\delta}
$$

where $S_{J}=\int_{R}^{1} J(z) F(z)$ is the average value for the firm of a filled job. The wage rate is determined as a solution to the problem (6) in the main text. To derive the first order condition of the problem, differentiate the right hand side of (6) with respect to $w(x)$ and set equal to zero to get

$$
\beta(J(x)-V) \Omega_{W}+(1-\beta)(W(x)-U) \Omega_{J}=0
$$

where $\Omega_{W}=\frac{\partial(W(x)-U)}{\partial w(x)}$ and $\Omega_{J}=\frac{\partial(J(x)-V)}{\partial w(x)}$ and both $W(x)-U$ and $J(x)-V$ are assumed to be strictly positive. Utilizing the formulas (1), (4), (A.1) and (A.2) we can derive expressions for the two derivatives as follows: $\Omega_{W}=\frac{1-t}{r+\delta}$ and $\Omega_{J}=-\frac{1+s}{r+\delta}$. Substituting these in (A.3) and some manipulation then yields (7) in the main text.

\section{B Derivation of the Equilibrium with Taxes}

Substitution of (A.1), (A.2) and (9) in the wage rule (7) and solving explicitly for the wage rate yields 


$$
w(x)=\frac{\beta x}{1+s}+\frac{1-\beta}{1-t}(r U+g)
$$

which shows that the wage rate is a weighted average of the fall back position of the worker, $r U$, and the productivity of a match $x$, both of which are corrected for the relevant taxes. Substituting this in (A.2), under (9) and rearranging then gives

$$
(r+\delta) J(x)=(1-\beta) x-\frac{1+s}{1-t}(1-\beta)(r U+g)+\delta S_{J}
$$

To get a more convenient expression for the value of a filled job, we notice that $J(x)$ is linear in $x$ and develop the Taylor series around $J(R)=0$ to get

$$
J(x)=\frac{1-\beta}{r+\delta}(x-R)
$$

Applying (B.2) at the level of reservation productivity $(x=R)$ and further substituting (B.3) for $J(z)$ yields

$$
r U+g=\frac{(1-t) R}{(1+s)}+\frac{(1-t) \delta}{(1+s)(r+\delta)} \int_{R}^{1}(z-R) d F(z)
$$

To express the left hand side more conveniently, apply the wage equation (7) to $x=1$ with (9) binding to get

$$
W(1)=U+\frac{(1-t) \beta}{(1+s)(1-\beta)} J(1)
$$

Then notice that with (9) binding, (4) implies

$$
J(1)=\frac{c}{q(\theta)}
$$

which shows that for a given labor market tightness, the value of a new match increases in the recruiting cost, $c$.

To derive another independent equation in the two unknowns, apply (B.3) to $x=1$ and substitute (B.6) for the value of a job to get (12) in the main text. Then, substituting (B.5) and (B.6) in (1) yields

$$
r U=b-a+\frac{(1-t) \beta c \theta}{(1-\beta)(1+s)}
$$


where we utilized $q=\theta^{-1} m(\theta)$. Substituting (B.7) in (B.4) gives equation (11) in the main text. Also notice that substituting (B.7) in (B.1) yields yet another useful form of the wage equation

$$
w(x)=(1-\beta) \frac{b-a+g}{1-t}+\beta \frac{x+c \theta}{1+s}
$$

which shows the dependency of wages (for given labor market tightness) on the value of leisure $b$ search cost $a$ and the cost of holding a vacancy $c$. Wages depend positively on the labor market tightness, because the expected cost for the firm to find another match increases.

\section{Distribution of the Productivity Shock}

Assume productivity shock is uniformly distributed in the interval $[0,1]$. Then $f(z)=1$ and, consequently, we have

$$
\int_{R}^{1}(z-R) d F(z)=\int_{R}^{1}(z-R) d z=\frac{1}{2}(1-R)^{2}
$$

Furthermore,

$$
F(R)=\int_{0}^{R} d z=R
$$

and

$$
\int_{R}^{1} z d F(z)=\int_{R}^{1} z d z=\frac{1-R^{2}}{2}
$$

\section{Tax Revenues at the Steady State}

First notice that the stock of matches with productivity $x=1, n_{1}$ evolves according to

$$
\frac{d n_{1}}{d t}=m(\theta) u-\alpha_{1} \delta(1-u)(1-F(R))-\alpha_{1} \delta(1-u) F(R)
$$

where $\alpha_{1}$ is the share of matches with productivity $x=1$ of all matches. The three terms on the right hand side represent creation of new jobs, revaluation 
of jobs with $x=1$ and destruction of jobs with $x=1$, respectively. Setting the right hand side equal to zero and solving for $\alpha_{1}$ yields

$$
\alpha_{1}=\frac{m(\theta) u}{\delta(1-u)}=F(R)
$$

where the second equality follows from (8) holding in the steady state. Next, consider the revenue from the labor income tax at the steady state. For the proportional part, the revenue is given by

$$
T_{t}=\left(w(1) F(R)+\int_{R}^{1} w(z) d F(z)\right)(1-u) t
$$

For the constant part the revenue is simply given by

$$
T_{g}=(1-u) g
$$

Substituting (B.8) for $w(x)$ and utilizing $f(x)=1$ and $F(R)=R$ (see Appendix C) we get

$$
\int_{R}^{1} w(x) d F(x)=(1-R)\left(\frac{1-\beta}{1-t}(b-a+g)+\frac{\beta}{1+s}\left(c \theta+\frac{1+R}{2}\right)\right)
$$

Substituting this in (D.1) and applying (B.8) for $w(1)$ then yields

$$
T_{t}=\left(\frac{1-\beta}{1-t}(b-a+g)+\frac{\beta}{1+s}\left(c \theta+1-\frac{1}{2}(1-R)^{2}\right)\right)(1-u) t
$$

Repeating similar procedure for the payroll tax yields

$$
T_{s}=\left(\frac{1-\beta}{1-t}(b-a+g)+\frac{\beta}{1+s}\left(c \theta+1-\frac{1}{2}(1-R)^{2}\right)\right)(1-u) s
$$

Combining (D.2), (D.3) and (D.4), the total revenue $T=T_{t}+T_{g}+T_{s}$ becomes as expressed by (33) in the main text. 


\section{References}

[1] Altenburg, L. and Straub, M. (2002): Taxes on Labour and Unemployment in a Shirking Model with Union Bargaining, Labour Economics 8, 721-744.

[2] Aronsson, T., Wikström, M., and Brännlund R. (1997): Wage determination under non-linear taxes: Estimation and an application to panel data, Oxford Economic Papers, 49, 404-418.

[3] Booth, A. L. (1995): The Economics of the Trade Union, Cambridge University Press.

[4] CEPR (1995): Policies to Fight Unemployment in Alogoskoufis, G. et al: Unemployment : Choices for Europe, Monitoring European Integration 5 .

[5] Daveri, F. and Tabellini, G. (2000): Unemployment, Growth and Taxation in Industrial Countries, Economic Policy, 49-104.

[6] EU (2000): European Union Employment Policy Guidelines 2000.

[7] Hansen, C.T., Pedersen, L.H. and Slök, T. (2000): Ambiguous Effects of Tax Progressivity - theory and Danish Evidence, Labour Economics, Vol 7, 335-347.

[8] Hersoug, T. (1984): Union Wage Responses to Tax Changes, Oxford Economic Papers 36, 37-51.

[9] Hoel, M. (1990): Efficiency Wages and Income Taxes, Journal of Economics 51, 89-99.

[10] Holm, P., Sinko, P. and Tossavainen, P. (1999): Labour Market Policy and Unemployment - A Job Flow Model of Finland, Government Institute for Economic Research Discussion Paper No. 210.

[11] Holmlund, B. and Kolm, A-S. (1995): Progressive Taxation, Wage Setting and Unemployment - Theory and Swedish Evidence, Swedish Economic Policy Review 2, 423-460.

[12] Hosios, A.J. (1990): On the Efficiency of Matching and Related Models of Search and Unemployment, Review of Economic Studies 57, 279-298. 
[13] Kiander, J., Kilponen, J. and Vilmunen, J. (2004): Labour Taxation, Public Finance and Wage-Determination: Evidence from OECD Countries, European Journal of Political Economy, Vol. 20, 983-999.

[14] Kilponen, J. and Sinko, P. (2005): Taxation and Centralised Wage Setting: The Case of Endogenous Labour Supply, forthcoming in Scottish Journal of Political Economy.

[15] Koskela, E. and Vilmunen, J. (1996): Tax Progression is Good for Employment in Popular Models of Trade Union Behavior, Labour Economics 3, 65-80.

[16] Lambert, P.J. (2001): The Distribution and Redistribution of Income, 3rd Edition, Manchester University Press.

[17] Layard, R., Nickell, S. and Jackman, R. (1991): Unemployment Macroeconomic Performance and the Labour Markets, Oxford University Press.

[18] Lockwood, B. and Manning, A. (1993): Wage Setting and the Tax System - Theory and Evidence for the UK, Journal of Public Economics, $52,1-29$.

[19] Millard, S.P. and Mortensen, D.T (1997) : The Unemployment and Welfare Effects of Labour Market Policy: A Comparison of the UK and the USA, in Snower, D.J. and de la Dehesa, G. (eds.): Unemployment Policy: Government Options for the Labour Market, CEPR, 545-578.

[20] Ministry of Labour (2002): Impact of the EES; National evaluation of the effects of the European Employment strategy in Finland, Final Report.

[21] Mortensen, D.T. and Pissarides, C.A. (1994): Job Creation and Job Destruction in the Theory of Unemployment, Review of Economic Studies 61, 397-415.

[22] Mortensen, D.T. and Pissarides, C.A. (1999): New Developments in Models of Search in the Labour Market, in Ashenfelter, O.C. and Card, D. (eds.) Handbook of Labor Economics, Vol. 3B, 2567-2627, NorthHolland. 
[23] Mortensen, D.T. and Pissarides, C.A. (2002): Taxes, Subsidies and Equilibrium Labor Market Outcomes, Centre for Economic Performance, LSECEP Discussion Papers No. 0519.

[24] Musgrave, R.A. and Thin, T. (1948): Income Tax progression, 19291948, Journal of Political Economy 56, 498-514.

[25] Petrongolo, B. and Pissarides, C. (2001): Looking into the Black Box: A Survey of the Matching Function, Journal of Economic Literature, Vol. XXXIX, June, 390-431.

[26] Pisauro, G. (1991): The Effect of Taxes on Labour in Efficiency Wage Models, Journal of Public Economics 46, 329-345.

[27] Pissarides, C.A. (1998): The Impact of Employment Tax Cuts on Unemployment and Wages; The Role of Unemployment Benefits and Tax Structure, European Economic Review 42, 155-183.

[28] Pissarides, C.A. (2000): Equilibrium Unemployment Theory, 2. edition, MIT Press, Cambridge.

[29] Prescott, E.C. (2004): Why Do Americans Work So Much More Than Europeans, Federal Reserve Bank of Minneapolis Quarterly Review, Vol 28, No. 1, 2-13.

[30] Rasmussen, B.S. (1998): Long Run Effects of Employment and Payroll Taxes in an Efficiency Wage Model, Economics Letters 58, 245-253.

[31] Shapiro, C. and Stiglitz, J.E. (1984): Equilibrium Unemployment as a Worker Discipline Device, American Economic Review 74, 433-444.

[32] Schneider, K. (2005): Union wage setting and progressive income taxation with heterogeneous labor: theory and evidence from the German income tax reforms 1986-1990, Labour Economics 12, 205-222.

[33] Sörensen, P.B. (1999): Optimal Tax Progressivity in Imperfect Labour Markets, Labour Economics 6, 435-452. 